\title{
Indirect predator effects on age-0 northern rock sole Lepidopsetta polyxystra: growth suppression and temporal reallocation of feeding
}

\author{
Clifford H. Ryer*, Thomas P. Hurst \\ Fisheries Behavioral Ecology Program, Alaska Fisheries Science Center, National Marine Fisheries Service/ \\ National Oceanic \& Atmospheric Association (NMFS/NOAA), Hatfield Marine Science Center, 2030 SE Marine Science Dr., \\ Newport, Oregon 97365, USA
}

\begin{abstract}
Field observations reveal that age-0 northern rock sole avoid feeding during daylight hours, instead, concentrating their feeding at dusk. Laboratory studies demonstrate these fish to be extremely risk averse in their behavior relative to predators. We hypothesized that dusk feeding may be an adaptation to mitigate the conflict between feeding and predator avoidance, which if unresolved, could negatively affect not only short term survival, but growth as well. We designed experiments to examine firstly, whether growth of juvenile northern rock sole is suppressed by the perception of chronic predation risk, and secondly, whether growth suppression is alleviated by allowing fish to feed at dusk. Replicate groups of 15 fish were grown in the presence or absence of predators ( 2 walleye pollock) and given access to food under either daylight or dusk conditions over a 6 wk period. Flatfish growth was independently and negatively influenced by both predator presence and daylight conditions; fish fed in daylight in the presence of predators lost weight, while those fed under dusk conditions in the absence of predators grew faster. These results are consistent with our hypothesis that dusk feeding is a behavior that mitigates effects of predation, not only upon survival, but also upon growth. Further, if predator abundance influences growth, as suggested by our data, indirect predator effects such as growth suppression may significantly influence the quality of nursery habitats that differ in predator abundance.
\end{abstract}

KEY WORDS: Juvenile flatfish $\cdot$ Growth rate $\cdot$ Behavioral inhibition $\cdot$ Habitat quality $\cdot$ Non-lethal effects

\section{INTRODUCTION}

Having evolved an intimate association with the seafloor, flatfish are some of the most cryptic of fish species, relying upon a highly specialized detection minimization strategy to avoid predation. Along with their unique morphological adaptations, dermal chromatophores allow flatfish to mimic sediment color and texture (Ramachandran et al. 1996, Ellis et al. 1997), rendering them nearly invisible. The effectiveness of these physical attributes is further enhanced by behavioral tactics; sensing the approach of threat, juvenile flatfish cease movement, lower their body profile and/or bury in the sediment (Ryer et al. 2004, Lemke \& Ryer 2006a).

Although effective, detection avoidance through inactivity and burial comes at a cost, as it is incompatible with foraging. Where predation risk is intermittent, this cost may be negligible; however, under chronic risk the potential exists for behavioral inhibition of feeding that leads to predator-induced growth suppression. Through growth suppression, predators may influence the individual fitness of prey and prey population growth through processes other than direct removal (Lima 1998). Further, since predator density may vary spatially, predator-induced growth suppres- 
sion may play a role in determining habitat quality and the ultimate contribution of various juvenile habitats to the support of adult populations.

Acceptance of suppressed growth and its consequences for fitness may not represent a viable longterm strategy for many species. In some instances, animals may acclimate to elevated predation risk and resume feeding (threat allocation hypothesis, Lima \& Bednekoff 1999). In other instances, animals may emigrate to habitats where predation risk is lower (Crowder \& Cooper 1982, Werner \& Hall 1988, Ryer et al. 2007). Another solution is for animals to reallocate feeding to times of the day when they are less vulnerable to predation. Salmonids have been observed to shift feeding to times when predators are less active or they themselves are less likely to be detected (Fraser \& Metcalfe 1997, Metcalfe et al. 1998). In nursery embayments around Kodiak Island, Alaska, age-0 northern rock sole Lepidopsetta polyxystra (hereafter rock sole) feed predominantly at dusk, behavior that Hurst et al. (2007) speculated was associated with avoidance of predation. In another study of age- 0 juveniles of 3 species, viz. rock sole, English sole Parophrys vetulus and Pacific halibut Hippoglossus stenolepis, rock sole behavior was the most conservative, or 'risk averse' of the three (Lemke \& Ryer 2006a). Rock sole were more likely to remain buried and inactive than the other species, either in the presence or absence of predators. Perhaps as a consequence, rock sole were the least vulnerable to predation in standardized predator challenges (Ryer et al. 2004, Lemke \& Ryer 2006b). Given their 'risk averse' nature, we hypothesized that the adoption of a dusk feeding periodicity could be the means by which rock sole have mitigated this conflict between feeding and predator avoidance. We conducted an experiment to determine whether chronic predation risk would suppress the growth of juvenile rock sole, and if so, whether growth suppression would be mitigated by allowing fish access to food under conditions that lessened their conspicuousness to predators, i.e. low light conditions simulating dusk. We tested these hypotheses by comparing the growth of age- 0 rock sole fed under daylight conditions with that of fish fed under light levels simulating dusk, both in the presence and absence of predators.

\section{MATERIALS AND METHODS}

Age-0 rock sole were collected from Chiniak Bay, Kodiak Island, Alaska, using a beam trawl ( $2 \mathrm{~m}$ wide, $3 \mathrm{~mm}$ mesh size), then transported to the US National Marine Fisheries Service (NMFS) laboratory at the Hatfield Marine Science Center in Newport, Oregon, USA. Fish were maintained in $2 \mathrm{~m}$ diameter tanks with a thin layer of sand on the bottom and flow-through seawater at $9^{\circ} \mathrm{C}$ $\left( \pm 1^{\circ} \mathrm{C}\right)$. Rock sole were fed to satiation thrice weekly on $2 \mathrm{~mm}$ food pellets. Predators used in experiments were age- 3 walleye pollock Theragra chalcogramma (28-35 cm total length). These pollock had been raised from age-0 juveniles in the laboratory with no experience of live prey, and preliminary observations indicated they rarely consumed juvenile flatfish. However, experience with similar predator-prey experiments (Lemke \& Ryer 2006a) suggested that the juvenile rock sole would nevertheless respond to the presence of pollock with stereotypic anti-predator behavior.

Growth trials were conducted under conditions simulating both daylight and dusk, utilizing 6 replicate $2.9 \mathrm{~m}$ diameter (6400 l) arenas, also supplied with seawater at $9^{\circ} \mathrm{C}\left( \pm 1^{\circ} \mathrm{C}\right)$. Each arena bottom was covered by a $3 \mathrm{~cm}$ deep layer of a 2:1 mixture of coarse $(1.0 \mathrm{~mm})$ and medium $(0.5 \mathrm{~mm})$ sand, which allowed age- 0 flatfish to bury completely. Rock sole in each of 6 groups (15 fish to a group) were measured for total length (nearest $\mathrm{mm}$ ) and weighed (nearest $0.01 \mathrm{~g}$ ), prior to introduction to arenas. Three randomly chosen arenas also received 2 predators, i.e. pollock. Both predators and rock sole were accustomed to a $12: 12 \mathrm{~h}$ photoperiod, with darkness from 19:00 to 07:00 $h$; for this first set of 'daylight' trials this photoperiod was continued. In the first set of trials, light levels in the bottom center of the arenas was approximately $2 \mu \mathrm{mol}$ photons $\mathrm{m}^{-2} \mathrm{~s}^{-1}$ during the day and $<1 \times 10^{-7} \mu \mathrm{mol}$ photons $\mathrm{m}^{-2} \mathrm{~s}^{-1}$ at night. This daytime illumination is typical of $12 \mathrm{~m}$ bottom mid-day light levels at our Holiday Beach Kodiak nursery site, with $12 \mathrm{~m}$ corresponding to approximately the center of the age- 0 rock sole depth distribution (Hurst et al. 2007). Both pollock and juvenile rock sole were fed 3 times weekly at 15:00 h. First, the pollock were fed to satiation on gel food $\left(1 \mathrm{~cm}^{3}\right.$ cubes $)$, with all excess food immediately removed to preclude being consumed by northern rock sole. By feeding pollock first, we satiated the fish and precluded their consumption of flatfish food. Next, juvenile rock sole were fed a $5 \%$ ration (based upon the combined weights of fish for each arena) of commercial moist food pellets. Pellet energetic content was approximately $13.5 \mathrm{~kJ} \mathrm{~g}^{-1}$. Preliminary investigation revealed that these $2 \mathrm{~mm}$ pellets softened into a dilute paste within $2 \mathrm{~h}$, after which the juvenile flatfish were unable to effectively feed upon them. This assured that the food was available for only a relatively short period of time. After $3 \mathrm{wk}$, all rock sole were netted, measured and weighed, and then returned to their respective arenas. Rations were recalculated. After another $3 \mathrm{wk}$, fish were again removed from arenas, measured and weighed.

The second set of 'dusk' trials was identical in all respects to the first, except for the photoperiod and that the fish were given access to food during a dusk transi- 
tion period. In these dusk trials, the photoperiod was shifted such that daylight occurred from 06:30 to 15:00 h and night from 18:30 to 03:00 h, with $3.5 \mathrm{~h}$ dusk and dawn transitions from 15:00 to $18: 30 \mathrm{~h}$ and 03:00 to 06:30 h, respectively. Light levels for day and night were the same as in the previous trials. The initiation of dusk (15:00 h) began with the turning off of the overhead fluorescent light, and the turning on of overhead 'white' light emitting diodes (LEDs), which provided a light level of approximately $2 \times 10^{-2} \mu \mathrm{mol}$ photons $\mathrm{m}^{-2}$ $\mathrm{s}^{-1}$. Rock sole were fed at 15:30 h, which typically took $5 \mathrm{~min}$. Immediately after food was introduced to the arenas, the LED light level was gradually lowered over a 5 min period to approximately $2 \times 10^{-3} \mu \mathrm{mol}$ photons $\mathrm{m}^{-2} \mathrm{~s}^{-1}$. This dusk light level $\left(2 \times 10^{-3} \mu \mathrm{mol}\right.$ photons $\mathrm{m}^{-2}$ $\mathrm{s}^{-1}$ ), while 3 orders of magnitude below the daytime illumination, is still 2 orders of magnitude above the threshold at which age- 0 rock sole lose the ability to capture prey using visual cues (Hurst et al. 2007). LEDs remained at this level until 18:30 $\mathrm{h}$, when they were turned off $\left(<1 \times 10^{-7} \mu \mathrm{mol}\right.$ photons $\left.\mathrm{m}^{-2} \mathrm{~s}^{-1}\right)$. The dawn transition began with the LEDs turned on at a level of $2 \times 10^{-3} \mu \mathrm{mol}$ photons $\mathrm{m}^{-2} \mathrm{~s}^{-1}$ at 03:00 h. Light remained constant until 06:30 $\mathrm{h}$ when the fluorescent lights were switched on $\left(2 \mu \mathrm{mol}\right.$ photons $\left.\mathrm{m}^{-2} \mathrm{~s}^{-1}\right)$. We assume that any incidental differences in light cycles between daylight and dusk treatments in no way confounded our comparison of illumination level during feeding. More specifically, we assume that the sudden illumination shifts in the daylight trials did not stress fish, thereby influencing growth, in comparison to the dusk trials where these shifts were more gradual. In holding tanks, we routinely observed rock sole swimming to the water's surface at the approach of humans, in anticipation of feeding, behavior that would not be expected in stressed fish (C. Ryer pers. obs.).

Although trials at the 2 light levels were conducted consecutively, all fish were from a single cohort. A comparable range of fish sizes was assigned to each trial. As a result, neither mean $( \pm \mathrm{SD})$ fish total length $(65.9 \pm 8.1 \mathrm{~mm})$ nor mean $( \pm \mathrm{SD})$ fish weight $(3.54 \pm$ $1.32 \mathrm{~g})$ at the initiation of trials differed as a consequence of predator presence/absence (length: $F_{1,2}=$ $0.11, \mathrm{p}=0.775$; weight: $\left.F_{1,2}=0.62, \mathrm{p}=0.512\right)$, light level (length: $F_{1,2}=4.37, \mathrm{p}=0.172$; weight: $F_{1,2}=0.05$, $\mathrm{p}=0.849$ ) or their interaction (length: $F_{1,2}=0.06, \mathrm{p}=$ 0.826; weight: $\left.F_{1,2}=0.00, \mathrm{p}=0.993\right)$. Mass specific growth rates (SGR) for each fish were determined for each of 2 consecutive 3 wk growth periods. In lieu of individual markings, the fish in each tank were assumed to have maintained a rank order in body size throughout the experiment. In cases of predation without recovery of dead prey, the size rank of the missing fish was identified through pairing of final sizes of survivors with initial sizes in the order that yielded the lowest variation in SGR. Fish lost to predation or scavenging ( $n=15$, out of 180 total fish) were not included in analyses, which were conducted separately for weeks 1 to 3 and 3 to 6 of the experiment. Similarly, another 18 fish died, were recovered, accounted for and eliminated from analysis. The number of fish left after 6 wk ranged between 9 and 14 for each trial, with no difference in mortality attributable to predator presence/absence $\left(F_{1,8}=2.88, \mathrm{p}=0.128\right)$, light $\left(F_{1,8}=0.02\right.$, $\mathrm{p}=0.881)$ or their interaction $\left(F_{1,8}=1.17, \mathrm{p}=0.312\right)$. The effects of predator presence and light level on growth rates of rock sole were examined with factorial ANOVA. Growth rates of individual fish were used as the level of observation in the analysis, with replicate tanks ( $\mathrm{n}=3$ per treatment combination) treated as a random factor nested within light and predator treatment.

\section{RESULTS}

During the first $3 \mathrm{wk}$ of the experiment, rock sole growth was influenced by both predator presence and timing of feeding relative to the diel light cycle (Fig. 1). In both light conditions, predator presence resulted in significantly lower growth rates $\left(F_{1,8}=6.061, \mathrm{p}=\right.$

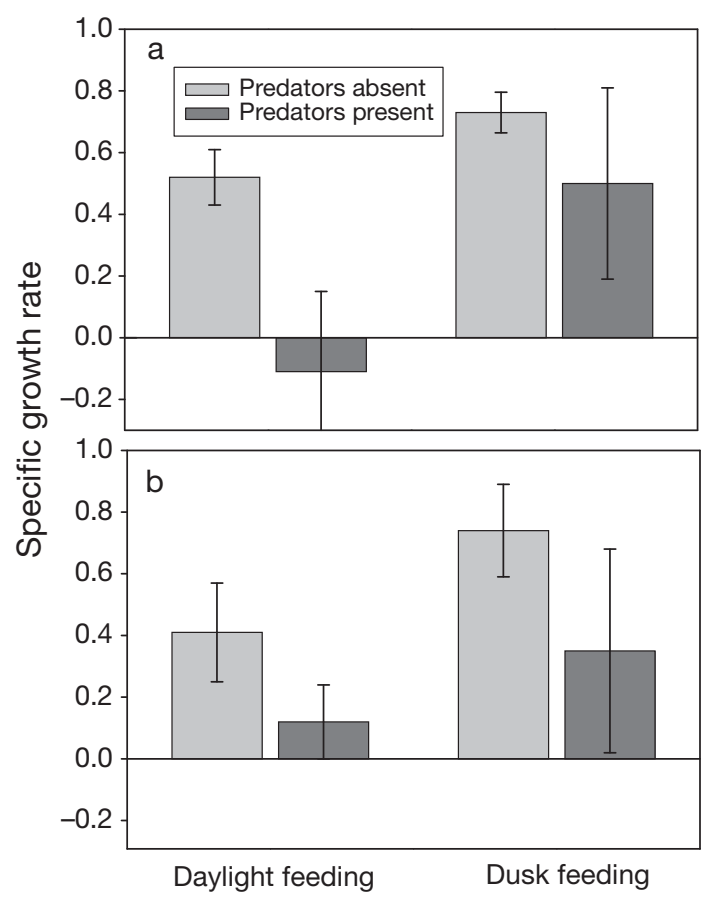

Fig. 1. Mean \pm SE mass specific growth rate (\% wt increase $\mathrm{d}^{-1}$ ) for replicate groups of fish during (a) the first $3 \mathrm{wk}$ and (b) the second $3 \mathrm{wk}$ of an experiment in which age- 0 rock sole were given access to food at light levels approximating either daytime or dusk conditions, both in the presence and absence of chronic predator presence. $\mathrm{n}=3$ for each bar 
0.039). Similarly, both in the absence and presence of predators, rock sole growth rates were higher when fish were fed under dusk conditions $\left(F_{1,8}=5.608, \mathrm{p}=\right.$ 0.045). There was no significant interaction effect between time of feeding and predator presence $\left(F_{1,8}=\right.$ $1.25, \mathrm{p}=0.30$ ), but the combined effects of daytime feeding and predator presence resulted in negative growth in this treatment.

Results during the second 3 wk of the experiment were generally similar, with highest growth rates observed in the absence of predators when fish were fed under dusk conditions. However, in this case, the effects of predator presence $\left(F_{1,8}=2.797, \mathrm{p}=0.132\right)$, feeding time $\left(F_{1,8}=1.815, \mathrm{p}=0.215\right)$, and their interaction $\left(F_{1,8}=0.064, \mathrm{p}=0.807\right)$ were not significant.

These growth rate measurements were consistent with behavioral observations made during the experiments. Throughout the daylight period, rock sole generally remained buried. When food was introduced to the arenas, rock sole emerged from the sand and moved about the bottom consuming food pellets. It appeared that rock sole were inhibited by the presence of predators and daylight illumination and therefore less likely to emerge from the sediment to forage.

\section{DISCUSSION}

It is generally assumed that the principal effect of predators upon prey populations is the direct removal of prey via capture and consumption. Yet, indirect, non-consumptive predator effects also have the potential to influence prey behavior, growth and ultimately, fitness (Lima 1998). While many studies have demonstrated short-term suspension of feeding in response to perceived risk, fewer have demonstrated the longer term consequence of reduced growth (Nakaoka 2000, Pratt \& Fox 2002, Harter \& Heck 2006). By amputating damsel bug (Nabis spp.) mouthparts, Nelson et al. (2004) demonstrated that predator disturbance alone was sufficient to reduce population growth of their pea aphid Acyrthosiphon pisum prey. Aphids respond to damsel bug predators by reducing time spent feeding, presumably influencing individual growth and offspring production. Suppressive effects of predators upon hard clam Mercenaria mercenaria (Nakaoka 2000), walleye Stizostedion vitreum (Pratt \& Fox 2002) and juvenile pinfish Lagodon rhomboids (Harter \& Heck 2006) growth have also been documented. Rock sole confined to laboratory tanks with predators and with access to food only during daylight hours, arguably had to make the best of a bad situation. When confronting imminent predation risk, rock sole bury, remain motionless (Lemke \& Ryer 2006a) and suspend feeding (K. Boersma, C. Ryer, T. Hurst, S. Heppell, S.
Boersma unpubl. data), a tactic that facilitates detection avoidance (Ellis et al. 1997), but if utilized for an extended period, would impact growth. In our experiment, this indirect predation effect was intense enough to produce negative growth during the first 3 wk of the experiment. However, predator avoidance that results in a negative energetic balance is not a viable longterm strategy and at some point fish should begin feeding to avert starvation (Lima 1998, Lima \& Bednekoff 1999). Growth in rock sole may have rebounded somewhat during the subsequent $3 \mathrm{wk}$ period, although this was not statistically demonstrable.

Since reduced growth has negative consequences for fitness (Sogard 1997), it is expected that fish will seek to mitigate this effect through multifaceted responses (Lind \& Cresswell 2005) that allow for continued growth. For example, rather than simply increasing vigilance (Pulliam \& Caraco 1984) or time spent in highly structured habitats (Laurel et al. 2003, Ryer et al. 2004), prey may also concurrently modify how they interact with conspecifics, e.g. forming more cohesive schools (Ryer \& Olla 1996, Hurst 2007). Fish may also reallocate vulnerable activities to times when predators are less active or they themselves are less likely to be detected (Fraser \& Metcalfe 1997, Metcalfe et al. 1998). Juvenile fish are generally less vulnerable to visual predators during the night (Laurel et al. 2003). Perhaps as a consequence, juvenile flatfish spend less time buried when ambient illumination is low (Curran \& Able 1998, Stoner \& Titgen 2003). When fed under low illumination, age-0 rock sole appeared less inhibited in their feeding and, despite the presence of predators, grew at a rate closer to that of control fish. In Kodiak nursery embayments, juvenile rock sole abstain from daytime feeding, instead concentrating feeding during dusk (Hurst et al. 2007). Our laboratory experiment suggests this feeding periodicity is likely to be a response to predation. While juvenile flatfish have lowered visual acuity under nighttime illuminations, which reduces their encounter rates with prey (Hurst et al. 2007), shifting to a crepuscular foraging periodicity might nevertheless represent the best strategy for juvenile rock sole by balancing predation risk with foraging ability to minimize suppression of growth. The fact that growth was greater under dusk feeding conditions, regardless of predator presence or absence, suggests that this is partially an evolutionary response, rather than a strictly facultative behavioral tactic.

Our experiment was conducted in laboratory arenas at a predator density $\left(\sim 0.3 \mathrm{~m}^{-2}\right)$ that might seem unrealistic in many estuarine and/or coastal waters. However, juvenile rock sole did not rapidly acclimate to elevated predator density during $3 \mathrm{wk}$, despite low predation mortality ( $8 \%$ over $6 \mathrm{wk}$ ), attesting to the risk-averse nature of this species (Lemke \& Ryer 2006a). Despite 
this innate aversion to risk, their greater willingness to feed under low illumination suggests that ambient illumination plays an important role in modulation of feeding behavior in rock sole and is consistent with observed rock sole feeding in the wild (Hurst et al. 2007). This indicates that our experiment, although conducted under laboratory conditions, reflects the tradeoffs that determine when these fish feed.

Lastly, our results have implications for understanding habitat quality (Beck et al. 2001, Dahlgren et al. 2006). Realization of physiological growth potential in flatfish is traditionally considered to be under the control of ambient water temperature (Van der Veer \& Witte 1993, Hurst \& Abookire 2006) and food availability (Van der Veer et al. 1994). Our work suggests that growth of juvenile flatfishes can be further restricted by behavioral inhibition in response to predator presence. Unless juvenile fish can either emigrate or alter behavior so as to mitigate this effect, the higher mortality rates of fish in nursery grounds with abundant predators (a direct effect) will be compounded by reduced growth rates in those habitats (an indirect effect). Ryer et al. (2007) speculated that observed differences in rock sole growth between nursery embayments around Kodiak Island Alaska may represent differential growth suppression arising from local differences in predator abundance. As predation is typically size-selective (Sogard 1997), fish leaving nurseries at a smaller size may subsequently suffer higher mortality, contributing less to the adult population. Further research into predator induced growth suppression is warranted, as it may represent an important process influencing habitat quality for juvenile fish.

Acknowledgements. We thank M. Ottmar, P. Iseri and S. Haines for assistance with experiments and animal husbandry. C. Sweitzer assisted with manuscript preparation and A. Stoner and B. Laurel provided helpful discussion and feedback during various stages of this work. Three anonymous reviewers provided helpful comments on early drafts of this work. This project was supported, in part, by Grant R0301 from the North Pacific Research Board to C.H.R., I. Fleming, A. Abookire and A. Stoner.

\section{LITERATURE CITED}

Beck MW, Heck KW Jr, Able KW, Childers DL and 9 others (2001) The identification, conservation, and management of estuaries and marine nurseries for fish and invertebrates. Bioscience 51:633-641

Crowder LB, Cooper WE (1982) Habitat structural complexity and the interaction between bluegills and their prey. Ecology 63:1802-1813

Curran MC, Able KW (1998) The value of tethering fishes (winter flounder and tautog) as a tool for assessing predation rates. Mar Ecol Prog Ser 163:45-51
Dahlgren CP, Kellison GT, Adams AJ, Gillanders BM and 5 others (2006) Marine nurseries and effective juvenile habitats: concepts and applications. Mar Ecol Prog Ser 312: 291-295

Ellis T, Howell BR, Hughes RN (1997) The cryptic response of hatchery-reared sole to a natural sand substratum. J Fish Biol 51:389-401

Fraser NHC, Metcalfe NB (1997) The costs of becoming nocturnal: feeding efficiency in relation to light intensity in juvenile Atlantic salmon. Funct Ecol 11:385-391

Harter SL, Heck KL Jr (2006) Growth rates of juvenile pinfish (Lagodon rhomboids): effects of habitat and predation risk. Estuar Coast 29:318-327

Hurst TP (2007) Thermal effects on behaviour of juvenile walleye pollock: implications for energetics and food web models. Can J Fish Aquat Sci 64:449-457

Hurst TP, Abookire AA (2006) Temporal and spatial variation in potential and realized growth rates of age- 0 year rock sole. J Fish Biol 68:905-919

Hurst TP, Ryer CH, Ramsey JA, Haines SA (2007) Divergent foraging strategies of three co-occurring north Pacific flatfishes. Mar Biol 151:1087-1098

Laurel BJ, Gregory RS, Brown JA (2003) Predator distribution and habitat patch area determine predation rates on Age0 juvenile cod Gadus spp. Mar Ecol Prog Ser 251:245-254

Lemke JL, Ryer CH (2006a) Risk sensitivity in three juvenile (Age-0) flatfish species: does estuarine dependence promote risk-prone behavior? J Exp Mar Biol Ecol 333: $172-180$

Lemke JL, Ryer CH (2006b) Relative predation vulnerability of three juvenile (Age-0) North Pacific flatfish species: possible influence of nursery-specific predation pressures. Mar Ecol Prog Ser 328:267-273

Lima SL (1998) Nonlethal effects in the ecology of predatorprey interactions. Bioscience 48:25-34

Lima SL, Bednekoff PA (1999) Temporal variation in danger drives antipredator behavior: the predation risk allocation hypothesis. Am Nat 153:649-659

Lind J, Cresswell W (2005) Determining the fitness consequences of antipredation behavior. Behav Ecol 16: 945-956

Metcalfe NB, Fraser NHC, Burns MD (1998) State-dependent shifts between nocturnal and diurnal activity in salmon. Proc R Soc Lond B 265:1503-1507

Nakaoka M (2000) Nonlethal effects of predators on prey populations: predator-mediated change in bivalve growth. Ecology 81:1031-1045

Nelson EH, Matthews CE, Rosenheim JA (2004) Predators reduce prey population growth by inducing changes in prey behavior. Ecology 85:1853-1858

Pratt TC, Fox MG (2002) Influence of predation risk on the overwinter mortality and energetic relationships of young-of-year walleyes. Trans Am Fish Soc 131:885-898

Pulliam HR, Caraco T (1984) Living in groups! Is there an optimal group size? In: Krebs JR, Davies HB (eds) Behavioural ecology: an evolutionary approach, 2nd edn. Blackwell Scientific Publications, Oxford, p 122-147

Ramachandran VS, Tyler CW, Gregory RL, RogersRamachandran D, Duensing S, Pillsbury C, Ramachandran C (1996) Rapid adaptive camouflage in tropical flounders. Nature 379:815-818

Ryer CH, Olla BL (1996) Social behavior of juvenile chum salmon, Oncorhynchus keta, under risk of predation: the influence of food distribution. Environ Biol Fish 45: 75-83

Ryer CH, Stoner AW, Titgen RH (2004) Behavioral mechanisms underlying the refuge value of benthic habitat 
structure for two flatfishes with differing anti-predator strategies. Mar Ecol Prog Ser 268:231-243

Ryer CH, Stoner AW, Spencer ML, Abookire AA (2007) Predation threat modifies habitat preference by age- 0 northern rock sole Lepidopsetta polyxystra. Mar Ecol Prog Ser 342:227-238

Sogard SM (1997) Size-selective mortality in the juvenile stage of teleost fishes: a review. Bull Mar Sci 60: $1129-1157$

Stoner AW, Titgen RH (2003) Biological structures and bottom type influence habitat choices made by Alaska flatfishes.

Editorial responsibility: Kenneth Heck,

Dauphin Island, Alabama, USA
J Exp Mar Biol Ecol 292:43-59

Van der Veer HW, Witte JIJ (1993) The 'maximum growth/ optimal food condition' hypothesis: a test for 0-group plaice Pleuronected platessa in the Dutch Wadden Sea. Mar Ecol Prog Ser 101:81-90

Van der Veer HW, Berghahn R, Rijnsdorp AD (1994) Impact of juvenile growth on recruitment in flatfish. Neth J Sea Res 32:153-173

Werner EE, Hall DJ (1988) Ontogenetic habitat shifts in bluegill: the foraging rate-predation risk trade-off. Ecology 69:1352-1366

Submitted: March 6, 2007; Accepted: October 24, 2007 Proofs received from author(s): March 17, 2008 